\title{
Understanding the effects of exchange rates on the cost of living for expatriates and ordinary residents in Singapore and Hong Kong
}

\author{
Asia Competitiveness Institute, \\ Lee Kuan Yew School of Public Policy, \\ National University of Singapore, \\ Singapore \\ Email: spptkg@nus.edu.sg \\ Email: spplntd@nus.edu.sg \\ *Corresponding author
}

Khee Giap Tan* and Nguyen Trieu Duong Luu

\begin{abstract}
It is important to factor in the effect that exchange rates have on cost of living rankings while computing cost of living indices, as conversion of local prices into a common currency is imperative for any ranking of cities in different parts of the world. Considering that such computations are going to be affected by exchange rate levels in the different cities, this paper empirically analyses the cases of Singapore and Hong Kong to understand the impact of exchange rates on their cost of living rankings. Our simulation analysis for these two global Asian cities shows that exchange rate fluctuations have a significant impact on the cost of living rankings for both expatriates and ordinary residents. In addition, our study indicates that cities in the developed Western countries are more expensive for ordinary residents than cities in less developed countries elsewhere, especially in Asia. We attribute this to structural differences in labour cost between these two sets of countries.
\end{abstract}

Keywords: cost of living; expatriates; ordinary residents; exchange rates; Singapore; Hong Kong.

Reference to this paper should be made as follows: Tan, K.G. and Luu, N.T.D. (2017) 'Understanding the effects of exchange rates on the cost of living for expatriates and ordinary residents in Singapore and Hong Kong', Int. J. Markets and Business Systems, Vol. 3, No. 1, pp.64-92.

Biographical notes: Khee Giap Tan is the Co-Director at the Asia Competitiveness Institute. He is an Associate Professor at Lee Kuan Yew School of Public Policy, National University of Singapore.

Nguyen Trieu Duong Luu is a Research Associate at the Asia Competitiveness Institute, Lee Kuan Yew School of Public Policy, National University of Singapore.

This paper is a revised and expanded version of a paper entitled 'Annual update of indices on cost of living, wages and purchasing power for expatriates and ordinary residents for world's major 103 cities', presented at 2016 Annual Asia Competitiveness Institute Conference on Competitiveness Ranking of Subnational Economies and Public Policy Studies in Greater China, India, Indonesia and ASEAN, Singapore, 24-25 November 2016. 


\section{Introduction and motivation}

Cost of living, wages and purchasing power have been critical issues of policy importance globally. These are key indicators of a country's standard of living. While cost of living has been routinely measured at the national level by the annual consumer price index (CPI), a reliable index for tracking and comparing costs of living and purchasing power at the sub-national level is still lacking in the literature. Commercial surveys, while useful for compensation decisions for expatriate professionals, are inadequate as they do not account for differences in consumption patterns across cities. Further, such surveys lack theoretical foundations as well as scientific rigour that are critical for fruitful policy discourse.

In this context, one of the first comprehensive attempts to measure the cost of living for expatriates and ordinary residents across 103 cities was provided by Tan et al. (2015) and Tan and Luu (2016). It was one of the first attempts to distinguish between the cost of living for expatriates and ordinary residents. The popular academic literature, such as reports frequently published by the Economist Intelligence Unit (EIU) and Mercer, has usually ignored the issue of cost of living for ordinary residents and has instead only focused on constructing cost of living indices for expatriates. ${ }^{1}$

However, any study which endeavours to rank different cities in the world according to their cost of living has to convert the price data used in computing the cities' cost of living indices to a common currency. This move is intended to facilitate international comparisons. While this sounds like a reasonable strategy, some complications arise with respect to the exchange rates of various currencies that are integrated into the calculation of the cost of living indices. As a result, the ranking of a city, which is based on the value of its index, reflects not only its relative expensiveness with respect to the other cities, but also the relative strength of its currency. In other words, the position of a city's ranking is not decided purely by the price levels of its consumption items but also by its exchange rates.

The effect that exchange rates have on cost of living rankings is ever-present, as conversion of local prices into a common currency is imperative for any ranking of cities in different parts of the world to be constructed. For instance, the findings of Tan et al. (2015) who compute the cost of living rankings for expatriates and ordinary residents for 103 cities across the world are likely to be affected by exchange rate levels in the different cities (also see Tan and Luu, 2016). Using the results generated in this study as the starting point and our baseline case, we investigate the cases of Singapore and Hong Kong to understand the impact of exchange rates on the cost of living rankings.

Consider the case of Singapore. Between 2005 and 2013 the Singapore dollar appreciated by almost $25 \%$ against the US dollar ${ }^{2}$ - the common currency used to compare all prices in the analysis by Tan et al. (2015) and Tan and Luu (2016). In theory, the strong Singapore dollar ought to have pushed Singapore's cost of living rankings for expatriates and ordinary residents upwards because any generic increase in local prices over this period would be magnified during currency conversion. However, given that such exchange rate effects are not explicitly accounted for while computing the cost of living rankings, this paper undertakes an empirical exercise to understand how such exchange rate movements could possibly impact the cost of living rankings. We illustrate by focusing on the contrasting examples of Singapore and Hong Kong, both associated with very high cost of living by several popular reports. ${ }^{3}$ 
The remainder of the paper proceeds as follows. Section 2 provides a review of the literature surrounding cost of living indices and subsequently offers a succinct summary of the tangential human resource management literature which deals with the concept of expatriates. Section 3 explains the methodology employed to simulate the cost of living rankings for expatriates and ordinary residents. The results for Hong Kong and Singapore are discussed in Section 4 of this paper. Section 5 offers a comparison of cost of living across geographical regions based on our results factoring in exchange rate effects. Section 6 concludes the paper and also cites avenues for future research.

\section{Literature review}

The traditional economics literature has predominantly focused on constructing cost of living indices to measure the changes in costs of consumption required to sustain a standard of living. This has been the broader conceptual framework to measure CPIs in several advanced economies like the United States of America (USA). The literature relating to whether a cost of living index should be the guiding basis for the measurement of CPI is quite old and still continues to this day (For a detailed discussion, see Triplett, 2000).

As mentioned, the measurement of prices and their rate of change (i.e., inflation) are of critical importance to the study of economics. However, measuring this change in the cost of living presents considerable difficulties, due to the sheer abundance of goods and services in today's markets. Further price fluctuations induced by technological change and variables impacting costs and quality result in consumers altering their consumption patterns. With increasing affluence, demand has also gradually gravitated towards services and to goods and services with superior quality and increased variety and convenience. This trend bolstered by rapid technological advancement has resulted in an ever-increasing plethora of goods and services (e.g., high-tech consumer products and IT services) over the past few decades, making the process of capturing price fluctuations comparatively more difficult (Boskin et al., 1998; Gordon and Griliches, 1997; Berndt et al., 1995).

A cost of living index could be used to capture price fluctuations and allow users to draw comparisons between time periods of the minimum expenditure required to attain similar states of well-being. It could also be defined as the ratio of the expenditure needed in the construction of a particular indifference curve of order preferences under two price systems (Gordon and Griliches, 1997; Pollak, 1975). The underlying assumption for this index is that the average utility level and the impact of other factors (encompasses government transfers, taxes, impact of disasters and epidemics) are held constant.

There are two approaches to measuring cost-of-living indices. One approach utilises estimated systems of demand equations. However, one weakness of this approach is that it becomes untenable and difficult to implement at detailed disaggregation levels. This is owing to the fact that the number of parameters requiring estimation in a comprehensive consumer demand system increases with the square of (one less than) the number of commodities. Another weakness of this approach is that the data involved in these studies is subject to significant aggregation, resulting in the underestimation of their substitution bias estimate; the aggregation process could mask substitution in consumption inside categories (Boskin et al., 1998; Braithwait, 1980; Goldberger and Gamaletsos, 1970). 
The second approach involves the calculation of index numbers, usually at a highly disaggregated level. The Laspeyres index is the best-known index number formula. The Laspeyres index could be mathematically expressed as follows:

$$
L\left(P_{1}, P_{0}\right)=\sum P_{1} X_{0} / \sum P_{0} X_{0}=\sum P_{1} X_{0} / Y_{0}
$$

where

$P_{1} \quad$ comparison price

$P_{0}$ reference price

$X_{0}$ total consumption in the base year

$Y_{0}$ actual expenditure.

The above equation is the ratio of the costs of a basket of goods in a specific time period (for which statistical results are collated) under two separate price sets. This index measures fluctuations in the cost of a fixed basket of goods. It is predicated on the assumption that there is no substitution triggered by price changes. Consequently, this deliberate omission of the substitution effect results in an index that is prone to estimation errors (Afrait, 2004; Braithwait, 1980; Boskin et al., 1998).

Generally, traditional cost of living indices are subject to considerable bias. This could be due to the failure to implement necessary adjustments for changes in the quality of goods and services purchased by consumers. Additionally, they fail to adequately address the value of newly available goods to consumers. The situation is exacerbated by price variations across different retail establishments (Abraham et al., 1998). In the case of the earlier cited Laspeyres index, an upward bias could be due to the aforementioned failure to incorporate the impact of newly available products and services which provide similar or even greater utility levels to buyers. The introduction of improved new products and services (assuming if they gain widespread market acceptance) tend to exert considerable downward pressure on overall prices. However the impact of this trend is ignored, resulting in an index that could over-estimate the true cost of living (Stigler, 1961; Noe and von Furstenberg, 1972). This inherent positive substitution bias in the Laspeyres index has long been recognised in the academic literature (Dumagan and Mount, 1997).

In addition, these indices are often predicated on the implausible assumption that the environment is not subject to change, ignoring the fact that changes in demography, consumer trends and technology all have considerable impact on the cost of living (Gordon and Griliches, 1997). In an increasingly globalised world with its constantly evolving demographics, cost of living indices should also take into consideration the fact that the residents of a city often comprise the locals and expatriates. Costs of living between these two groups tend to be different because of their disparate lifestyles, incomes and spending patterns. This study builds on the pioneering effort in Tan et al. (2015) and Tan and Luu (2016) which distinguishes between the cost of living for locals and expatriates across cities worldwide. ${ }^{4}$

While the distinction between expatriates and ordinary residents is not evident in the literature, there appears to be a tangential literature relating to the field of human resource management that is of relevance here. To be sure, there is a dedicated body of literature that attempts to define and understand the characteristics of expatriates. 
In its simplest form, the broadest definition of expatriate which we also conform to in this paper is that it refers to a person living outside his or her native country. While this might be both a reasonable and convenient starting point for any empirical analysis such as what we do in this paper, the human resource management literature calls for a more nuanced discussion that will allow a clearer definition of who expatriates are.

In a sweeping review of literature, McNulty and Brewster $(2016,2017)$ for instance track the conceptual evolution of the term 'business expatriates,' which they distinguish from expatriates as business expatriates are those are living abroad but also employed in organisations. One of the important points underlined by McNulty and Brewster (2016, 2017 ) is that even after a comprehensive review of literature that spans over fifty years, there is an evident lack of clarity surrounding the term business expatriates. In fact, in a majority of cases, the characteristics of business expatriates are intertwined with expatriates in general. They go the extent of arguing that "...that there has been a sloppy and almost casual use of terminology, a failure to define terms adequately, or in many cases at all, and too many unstated assumptions about the people being researched that, collectively, has resulted in reducing understanding of the meanings of 'expatriate'. This problem means that the measures used in empirical studies may not accurately represent the underlying concept being tested" [McNulty and Brewster, (2016), p.28].

Arguing for greater construct clarity, the authors conclude by applying the so-called 'boundary conditions' that will bring more definitional clarity on who business expatriates refer to. Specifically, they identify four conditions, of which the first one relates to the fact that business expatriates must be organisationally employed. The second one emphasises that there has to be greater clarity about the temporal dimension of such expatriate employment. The third boundary condition pertains to ascertaining whether business expatriates attain citizenship in the host country they are employed as they cease to become one when they take up one. The final boundary condition they identify is regarding "the legal context in which expatriate employment is enacted and whether people have the right to stay, and are allowed to seek work legally, in a specific country" (p.44). Overall these conditions or attributes are meant to be the guiding principles for clearly identifying who a business expatriate is.

Dealing with a related issue, similar concerns have been echoed by Dabic et al. (2015) who provide a review of the evolving research on expatriates and their impact on business performance. Using bibliometric analysis to survey over four decades of human resource management literature dealing with expatriates, Dabic et al. (2015) show evidence that the literature is nascent and lacks a systematic and holistic approach to understanding the working of expatriates, and hence requires 'higher order content'.

A few relevant empirical papers in this field are also worth mentioning. Shay and Baack (2004) for instance focus on expatriate adjustment. Using data from 194 expatriate managers and 505 subordinates working in the multinational hotel industry, they probe whether the reasons for expatriate assignment have any influence in the expatriate adjustment process and specifically explore the relationship between different modes of adjustment and outcome measures such as expatriate effectiveness.

In an interesting piece of relevant research, Biemann and Andresen (2010) analyse the differences between assigned expatriates and self-initiated expatriates in management and executive positions. The question they focus on in the paper deals with how far these two categories of expatriates differ from each other with regard to their rationale for working abroad as well as the differences in terms of their career aspirations and finally in what way they differ in terms of their individual career management. They find 
evidence that self-initiated expatriates differ significantly from traditional expatriates who are sent abroad by their firms. ${ }^{5}$

Finally, Suutari and Tornikoski (2000) focus on the notion of compensation for expatriate. They highlight the challenges involved in empirical research on how to design appropriate compensation packages for expatriates. In other words, empirically what are the determinants of compensation packages for expatriates? Using expatriate compensation packages of Finnish expatriates, the authors present empirical evidence that a host of variables including sex, age, levels in the organisational hierarchy, nature of assignment, family situation, area of operation, and the nationality of the employer. They also allude to the importance of exchange rates in factoring in such compensation packages.

Overall, to sum up our discussion on the literature, there are two broad strands of literature that we have examined. The first strand of literature was more directly related to our study and empirical analysis dealing with cost of living. This mainly relates to the conventional economics literature on constructing cost of living indices using changes in costs of consumption required to sustain a standard of living as the proxy measure. The second strand of literature, tangential to our study, focused much more narrowly on the notion of expatriates since we deal with cost of living for both ordinary residents and expatriates in our paper. While there is virtually no study that makes such a distinction, the human resource management literature appears to have dedicated studies that focus on the evolving nature of research on expatriates. The short message from surveying over five decades of research on expatriates is that there are several definitional and conceptual ambiguities in how to define expatriates. Further, there is still quite a distance to cover in terms of obtaining a rigorous and holistic perspective on all relevant aspects of the role and functions of expatriates. While the overarching message from this strand of literature is interesting in its own right, we believe that the economics literature is much less concerned about such definitional ambiguities as the objectives motivating of our research are substantially different from those of the human resource management literature.

We next turn to our methodology of simulations that we undertake in this paper in the following section that will explicitly focus on how exchange rates affect cost of living ranking for both ordinary residents and expatriates.

\section{Methodology of simulations}

Following Tan et al. (2015) and Tan and Luu (2016), which remain the starting point for us in this paper, we let the exchange rates of the currencies in all 103 cities (against the US dollar) follow their actual trends. ${ }^{6}$ The simulation scenario is one where the exchange rate of the Singapore dollar is assumed to have remained unchanged between 2005 and 2013 while rates of the other currencies are kept as they are in reality. By comparing Singapore's simulated cost of living rankings for expatriates and ordinary residents with the city's actual rankings, we can verify the extent of the effect of a strong currency on cost of living for all.

For comparison purposes, a similar exercise is also carried out for Hong Kong. In this exercise, our prior assumption is that Hong Kong's simulated rankings would not differ much from its original rankings. Unlike Singapore, which adopts a managed floating 
exchange rate system, Hong Kong pegs its currency to the US dollar. As a result, if there is very little variation in the exchange rate between the Hong Kong dollar and the US dollar over the years studied in the paper, the simulated scenario is likely to be similar to the baseline scenario for Hong Kong. The following discussion explains the methodology of our empirical exercise.

\subsection{Cost of living rankings for expatriates}

Since the methodologies to obtain the cost of living ranking for expatriates and cost of living ranking for ordinary residents are different, the simulations for expatriates and ordinary residents also proceed differently. This section details the simulation methodology for expatriates.

First, let us recall that in the original analysis of cost of living elaborated in Tan et al. (2015), the cost of living index for expatriates in a city in a particular year is calculated as follows:

$$
\text { Cost of living index for expartriates in city } m=\frac{\sum_{i=1}^{n} P_{C, m, i} \times W_{i}}{\sum_{i=1}^{n} P_{U S, N Y, i} \times W_{i}} \times 100
$$

where

$\begin{array}{ll}m & \text { city } \\ C & \text { the country where city m is located in; } \\ N Y & \text { New York } \\ U S & \text { USA } \\ i & \text { item } \\ n & \text { number of items in the consumption basket for expatriates } \\ P_{C, m, i} & \text { average price of item } i \text { in city } m \text { of country } C \\ W_{i} & \text { weight of item } i \text { within cost of living index for expatriates. }\end{array}$

Exchange rates enter the calculation through the term $P_{C, m, i}$. This is the US dollar-denominated average price of consumption item $i$ in city $m$ of country $C$. To obtain this term, we first gather all local currency prices of item $i$ in city $m$ from the Economist Intelligence Unit (EIU) CityData. We then convert these prices into US dollars, proxy for missing data entries where necessary ${ }^{7}$ and take the average of all converted prices to get $P_{C, m, i}$. In doing the conversion we use the average yearly exchange rate between the local currency of city $\mathrm{m}$ and the US dollar ${ }^{8}$ in the year for which the index is calculated. For example, if we are computing the cost of living index for expatriates in Tokyo in year 2013, the 2013 exchange rate of the yen will be used. The whole procedure applies to all consumption items except for miscellaneous goods and services. Price data for miscellaneous goods and services, which are acquired from the UBS prices and earnings study, are reported in US dollar to begin with. Thus, no conversion is needed and the value of $P_{C, m, i}$ for this item is simply the raw data value.

Equation (1) is used to combine all $P_{C, m, i}$ with their respective weights, $W_{i}$, to obtain the cost of living index for expatriates in each city. The cost of living ranking for 
expatriates is then generated by arranging the indices in a descending order. In other words, a city which is ranked higher (lower) is the one which has a larger (smaller) index.

We conduct the simulation for all years between 2006 and 2013. In our simulation, the basic framework to compute the cost of living index for expatriates as explained above is preserved. Equation (1) is still used to calculate the indices for the city of interest, i.e., Singapore or Hong Kong and the other 102 cities. In fact, no change is made to the index computation process for the latter group, such that the indices for these cities under the simulation scenario are exactly the same as they were originally.

For the city of interest, however, some modifications are made to the calculation of the term $P_{C, m, i}$. For item $i$ which is not considered under miscellaneous goods and services, we still begin by collecting all of its local currency prices from the EIU CityData. Nonetheless, the conversion of these prices into US dollar is now carried out using the 2005 exchange rate, regardless of the year for which the index is being calculated. Proxies, where necessary, are still derived by the same method as in the original analysis. All converted prices of item i are then averaged to give us the simulated average price of item $i$.

$P_{C, m, i}$ for miscellaneous goods and services in the city of interest is also modified. The raw price data for this item has been pre-converted into US dollars using the actual exchange rate of city m's local currency in the year for which the data is reported. Thus, to reflect our simulation assumption that the city of interest has not experienced any exchange rate fluctuations after 2005, we first work out the price of miscellaneous goods and services in local currency and then re-convert it back to US dollar using the 2005 exchange rate. Specifically, the simulated average price of miscellaneous goods and services in the city of interest in any year which comes after 2005 is given by the following equation:

$$
\begin{aligned}
P_{C, \text { m, Miscellaneous }, T}^{\text {simulated }}= & P_{C, \text { mMiscellaneous }, T} \times \frac{\text { Exchange rate }_{C, T}}{\text { Exchange rate }_{C, 2005}} \\
& \forall T \in(2006,2007,2008,2009,2010,2011,2012 \text { and 2013) }
\end{aligned}
$$

where

$m$

C

Miscellaneous

$T$

$P_{C, m, \text { Miscellaneous }, T}$

$P_{C, m, M i s c e l l a n e o u s, T}$

Exchange rate $_{C, T}$
Singapore or Hong Kong

Singapore or Hong Kong, China

miscellaneous goods and services year

simulated average price of miscellaneous goods and services in city $m$ of country $C$ in year $T$

actual average price of miscellaneous goods and services in city $m$ of country $C$ in year $T$

yearly average exchange rate between country $C$ and the USA in year $T$ (expressed as local currency unit per US dollar)

Exchange rate $_{C, 2005}$ yearly average exchange rate between country $C$ and the USA in year 2005 (expressed as local currency unit per US dollar). 
After obtaining the simulated average prices for all consumption items in the city of interest, we plug them back into equation (1) to obtain the simulated cost of living index for expatriates in that city. We then re-rank all cities to generate a simulated cost of living ranking for expatriates and compare the simulated ranking of the city of interest with its original ranking. Findings from this comparison are discussed in Section 3.

An important underlying assumption for the simulation is that consumption patterns of expatriates are insensitive to exchange rate fluctuations. In other words, exchange rates do not affect the composition of an expatriate's consumption basket - the items in it and the importance of each item to him. This assumption is intuitive considering that consumption patterns are formed mainly from the expatriate's consideration of his wants and needs, his relative preferences between different consumption items as well as the relative quality of the goods and services in the basket. These factors are assumed to be unaffected by exchange rates. As a result of the assumption, the weight of each item in the cost of living index for expatriates, or the term $W_{i}$ in equation (1), is the same in both the original analysis and the simulation scenario.

\subsection{Methodology to simulate the cost of living rankings for ordinary residents}

Next, we recall that in the original analysis of cost of living elaborated in Tan et al. (2015) and Tan and Luu (2016), the cost of living index for ordinary residents in a city in a particular year is calculated as follows:

$$
\text { Cost of living index for ordinary residents in city } m=\frac{C P_{c, m}^{E I U} \times \frac{N P_{C}^{I C P}}{N P_{C}^{E I U}}}{C P_{U S, N Y}^{E I U} \times \frac{N P_{U S}^{I C P}}{N P_{U S}^{E I U}}}
$$

where

$m \quad$ city

$C \quad$ the country where city $m$ is located in

NY New York

US USA

$C P_{C, m}^{E I U}=\sum_{i=1}^{n} P_{C, m, i} \times W_{C, i}$

$i \quad$ item

$n \quad$ number of items in the consumption basket

$P_{C, m, i}$ average price of item $i$ in city $m$ of country $C$

$W_{C, i} \quad$ weight of item $i$ within cost of living index for ordinary residents in country $C$.

$N P_{C}^{I C P}=\frac{\text { index of nominal expenditure per capita for country } C}{\text { index of real expenditure per capita for country } C}$ 
index of nominal expenditure per capita for country $C$

$$
=\frac{\text { nominal expenditure per capita for country } C}{\text { nominal expenditure per capita of the world }}
$$

index of real expenditure per capita for country $C$

$$
=\frac{\text { real expenditure per capita for country } C}{\text { real expenditure per capita of the world }}
$$

$N P_{C}^{E I U}=$ mean $C P_{C, m}^{E I U}$ from all cities within country $C$.

Exchange rates enter the calculation through two channels. The first is the term $C P_{C, m}^{E I U}$ and its mean value, the term $N P_{C}^{E I U} \cdot C P_{C, m}^{E I U}$ is the weighted average of US dollar-denominated average prices of the consumption items in city $m$, country $C$. Structure-wise, this term is similar to the numerator of equation (1), except that the item weights in equation (3), $W_{C, i}$ are country-specific and represent the consumption patterns of ordinary residents in city $m$. Meanwhile, the average prices used to compute $C P_{C, m}^{E I U}$ or $P_{C, m, i}$ are precisely the ones used in equation (1) to calculate the cost of living for expatriates. The process through which these prices are obtained and the role that exchange rates play in the data treatment are already documented in the previous section and would not be repeated here.

The second channel is the term $N P_{C}^{I C P}$. This term can be understood as the US dollar-denominated price level per unit real consumption for ordinary residents living in country $C . N P_{C}^{I C P}$ in 2005 and 2011 are calculated based on data on nominal and real expenditure per capita in country $C$ reported in the International Comparison Programme (ICP) surveys for these years. Since the ICP data are not available for any other year, we construct the $N P_{C}^{I C P}$ for the 2006-2010 period and the 2012-2013 period by incorporating extra information on exchange rates and inflation rates. In particular, the $N P_{C}^{I C P}$ for any year $T$ within the $2006-2010$ period is calculated as follows:

$$
\begin{aligned}
N P_{C, T}^{I C P}= & N P_{C, 2005}^{I C P} \times \frac{\text { Exchange rate }_{C, 2005}}{\text { Exchange rate }_{C, T}} \times \prod_{i=2006}^{T}\left(1+\text { Inflatrion rate }_{C, t}\right) \\
& \forall T \in(2006,2007,2008,2009 \text { and } 2010)
\end{aligned}
$$

where

$$
\begin{array}{ll}
C & \text { country } \\
T & \text { year } \\
N P_{C, T}^{I C P} & N P_{C}^{I C P} \text { in year } T \\
\text { Inflation rate }_{C, t} & \text { yearly average inflation rate for country } C \text { in year } t \\
\text { Exchange rate }_{C, T} & \begin{array}{l}
\text { yearly average exchange rate between country } C \text { and the USA in } \\
\text { year } T \text { (expressed as local currency unit per US dollar). }
\end{array}
\end{array}
$$

Likewise, the $N P_{C}^{I C P}$ for any year $T$ within the 2012-2013 period is given by: 


$$
\begin{aligned}
N P_{C, T}^{I C P}= & N P_{C, 2011}^{I C P} \times \frac{\text { Exchange rate }_{C, 2011}}{\text { Exchange rate }_{C, T}} \times \prod_{t=2012}^{T}\left(1+\text { Inflation rate }_{C, t}\right) \\
& \forall T \in(2012 \text { and } 2013)
\end{aligned}
$$

where

$C$

$T$

country

year

$N P_{C, T}^{I C P}$

$N P_{C}^{I C P}$ in year $T$

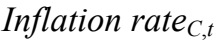

yearly average inflation rate for country $C$ in year $t$

Exchange Rate $_{C, T}$ yearly average exchange rate between country $C$ and the USA in year $T$ (expressed as local currency unit per US dollar).

Equation (3) is used to combine $C P_{C, m}^{E I U}, N P_{C}^{E I U}$ and $N P_{C}^{I C P}$ to obtain the cost of living index for ordinary residents in each city. The cost of living ranking for ordinary residents is then generated by arranging the indices in a descending order. In other words, a city which is ranked higher (lower) is the one which has a larger (smaller) index.

We conduct the simulation for all years in the study period except for 2005. In our simulation, the basic framework to compute the cost of living index for ordinary residents is preserved. Equation (3) is still used to calculate the indices for the city of interest, i.e., Singapore or Hong Kong and the other 102 cities. In fact, no change is made to the index computation process for the latter group, such that the indices for these cities under the simulation scenario are exactly the same as they were originally.

For the city of interest, however, we make the following modifications. Firstly, we adopt the procedure used in the simulations for expatriates to generate the simulated average price of each consumption item. Specifically, for any item $i$ which is not considered miscellaneous goods and services, we use the 2005 exchange rate of the local currency of the city of interest to convert local prices into US dollar, make proxies where necessary and average the converted prices to obtain the item's simulated average price. Meanwhile, for miscellaneous goods and services, we employ equation (2) to calculate $P_{C, m, \text { Miscellaneous, } T}^{\text {simulated }}$ The terms $C P_{C, m}^{E I U}$ and $N P_{C}^{E I U}$ for the city of interest are then recalculated with the simulated prices as inputs.

Second, the $N P_{C}^{I C P}$ term for the city of interest is also modified. From our earlier descriptions, it is easy to see that $N P_{C}^{I C P}$ for a certain year is essentially a price level pre-converted into US dollar using the actual exchange rate of country $C$ 's local currency in that year. To reflect our simulation assumption that the city of interest had not experienced any exchange rate fluctuations after 2005, we first work out the value of this price level in local currency and then re-convert it back to US dollar using the 2005 exchange rate. Specifically, the simulated $N P_{C}^{I C P}$ for the city of interest in any year which comes after 2005 is given by the following equation:

$$
\begin{aligned}
N P_{C, T}^{I C P, \text { simulated }}= & N P_{C, T}^{I C P} \times \frac{\text { Exchange rate }_{C, T}}{\text { Exchange rate }_{C, 2005}} \\
& \forall T \in(2006,2007,2008,2009,2010,2011,2012 \text { and 2013) }
\end{aligned}
$$


where

C

$T$

$N P_{C, T}^{I C P, \text { simulated }}$

$N P_{C, T}^{I C P}$

Exchange rate $_{C, T}$

Exchange rate $_{C, 2005}$
Singapore or Hong Kong, China

year

simulated $N P_{C}^{I P C}$ for the country $C$ in year $T$

actual $N P_{C}^{I C P}$ for the country $C$ in year $T$

yearly average exchange rate between country $C$ and the USA in

year $T$ (expressed as local currency unit per US dollar).

yearly average exchange rate between country $C$ and the USA in year 2005 (expressed as local currency unit per US dollar).

After obtaining the simulated terms $C P_{C, m}^{E I U}, N P_{C}^{E I U}$ and $N P_{C}^{I C P}$ for the city of interest, we plug them back to equation (3) to calculate the simulated cost of living index for ordinary residents in that city. We then re-rank all cities to generate a simulated cost of living ranking for ordinary residents and compare the simulated ranking of the city of interest with its original ranking. Findings from this comparison are discussed in Section 3 .

Just as before, the underlying assumption is that the consumption patterns of ordinary residents are insensitive to exchange rate fluctuations. The argument again is that consumption patterns are formed mainly based on ordinary residents' wants and needs, their relative preferences between the consumption items and the relative quality of the items. These factors are unlikely to be affected by exchange rates. As a result of this assumption, the set of item weights for ordinary residents in each country, $W_{C, i}$ is the same in both the simulation scenario and the original analysis.

\section{Empirical results}

Table 1 presents the simulation results for expatriates together with the original cost of living rankings for expatriates in Singapore and Hong Kong. Table 2 presents the simulation results for ordinary residents together with the original cost of living rankings for ordinary residents in Singapore and Hong Kong. The yearly average exchange rates of the Singapore dollar and the Hong Kong dollar against the US dollar over the study period are also shown in Tables 1 and 2.

Singapore's simulated rankings for both expatriates and ordinary residents' costs of living are lower than its original rankings in all the years for which the simulations are conducted. For example, in 2013, Singapore placed fourth in the cost of living ranking for expatriates in the original analysis. However, had the Singapore dollar not appreciated against the US dollar by almost $25 \%$ over the study period, Singapore would have been ranked 24th instead. In the other years, the simulated ranking for expatriates is always 15 th or below, while the original ranking was consistently 13 th or above. Not only so, while the original ranking displayed an increasing trend, the simulated ranking generally decreased between 2006 and 2011 before reversing to an increasing trend. Similarly, the simulated cost of living ranking for ordinary residents in Singapore is also always lower than the original cost of living ranking for ordinary residents. The simulated ranking is 
60th or below throughout the study period while the original ranking ranged between 60th and 48th place. Thus, as alluded to previously, the strong Singapore dollar has adversely helped to push Singapore's cost of living rankings upward.

Table 1 Original and simulated cost of living rankings for expatriates in Singapore and Hong Kong, 2005-2013

\begin{tabular}{|c|c|c|c|c|c|c|c|c|c|}
\hline & 2005 & 2006 & 2007 & 2008 & 2009 & 2010 & 2011 & 2012 & 2013 \\
\hline $\begin{array}{l}\text { Cost of living } \\
\text { ranking for } \\
\text { expatriates in } \\
\text { Singapore }\end{array}$ & 15 & 13 & 12 & 12 & 12 & 10 & 8 & 7 & 4 \\
\hline $\begin{array}{l}\text { Simulated cost of } \\
\text { living ranking for } \\
\text { expatriates in } \\
\text { Singapore }\end{array}$ & - & 15 & 21 & 31 & 25 & 24 & 33 & 22 & 24 \\
\hline $\begin{array}{l}\text { Cost of living } \\
\text { ranking for } \\
\text { expatriates in } \\
\text { Hong Kong }\end{array}$ & 5 & 6 & 10 & 17 & 13 & 12 & 12 & 9 & 11 \\
\hline $\begin{array}{l}\text { Simulated cost of } \\
\text { living ranking for } \\
\text { expatriates in } \\
\text { Hong Kong }\end{array}$ & - & 7 & 10 & 17 & 13 & 12 & 12 & 9 & 11 \\
\hline $\begin{array}{l}\text { Singapore dollar/US } \\
\text { dollar yearly average } \\
\text { exchange rate }\end{array}$ & 1.6645 & 1.5887 & 1.5068 & 1.4147 & 1.4538 & 1.3627 & 1.2572 & 1.2494 & 1.2510 \\
\hline $\begin{array}{l}\text { Hong Kong } \\
\text { dollar/US dollar } \\
\text { yearly average } \\
\text { exchange rate }\end{array}$ & 7.7775 & 7.7684 & 7.8020 & 7.7863 & 7.7517 & 7.7689 & 7.7844 & 7.7570 & 7.7566 \\
\hline
\end{tabular}

Source: Tan et al. (2015)

Meanwhile, Hong Kong's simulated rankings for both expatriates and ordinary residents' costs of living are almost always identical to its original rankings. In fact, there is no difference between the simulated cost of living ranking for ordinary residents in Hong Kong and its original counterpart. For expatriates, the simulated and original rankings are also the same for all years, except for 2006 when the two differ by only one place. These observations do not come as a surprise. As pointed out earlier on, the Hong Kong dollar is pegged against the US dollar. Thus, for Hong Kong, the simulated scenario is actually not very different from the reality hence Hong Kong's rankings remain almost unaltered after the simulation.

The simulation results serve to highlight the effect that the exchange rate of a city's local currency may have on its cost of living rankings. There is, however, another facet to the exchange rate story which is not captured by the simulation: exchange rate fluctuations in other cities may also influence the rankings of the city of interest. To see this aspect, one could analyse Singapore's recent rankings. 
Table 2 Original and simulated cost of living rankings for ordinary residents in Singapore and Hong Kong, 2005-2013

\begin{tabular}{|c|c|c|c|c|c|c|c|c|c|}
\hline & 2005 & 2006 & 2007 & 2008 & 2009 & 2010 & 2011 & 2012 & 2013 \\
\hline $\begin{array}{l}\text { Cost of living } \\
\text { ranking for ordinary } \\
\text { residents in } \\
\text { Singapore }\end{array}$ & 58 & 60 & 59 & 56 & 59 & 53 & 55 & 48 & 48 \\
\hline $\begin{array}{l}\text { Simulated cost of } \\
\text { living ranking for } \\
\text { ordinary residents in } \\
\text { Singapore }\end{array}$ & - & 60 & 62 & 65 & 62 & 64 & 69 & 66 & 67 \\
\hline $\begin{array}{l}\text { Cost of living } \\
\text { ranking for ordinary } \\
\text { residents in } \\
\text { Hong Kong }\end{array}$ & 56 & 58 & 60 & 62 & 60 & 62 & 63 & 62 & 59 \\
\hline $\begin{array}{l}\text { Simulated cost of } \\
\text { living ranking for } \\
\text { ordinary residents in } \\
\text { Hong Kong }\end{array}$ & - & 58 & 60 & 62 & 60 & 62 & 63 & 62 & 59 \\
\hline $\begin{array}{l}\text { Singapore dollar/US } \\
\text { dollar yearly average } \\
\text { exchange rate }\end{array}$ & 1.6645 & 1.5887 & 1.5068 & 1.4147 & 1.4538 & 1.3627 & 1.2572 & 1.2494 & 1.2510 \\
\hline $\begin{array}{l}\text { Hong Kong } \\
\text { dollar/US dollar } \\
\text { yearly average } \\
\text { exchange rate }\end{array}$ & 7.7775 & 7.7684 & 7.8020 & 7.7863 & 7.7517 & 7.7689 & 7.7844 & 7.7570 & 7.7566 \\
\hline
\end{tabular}

Source: Tan et al. (2015)

Consider, for example, the cost of living ranking for expatriates. Between 2011 and 2013, Singapore's actual ranking rose from eighth to fourth place. The yearly average exchange rate of the Singapore dollar against the US dollar was rather stable during this period. In climbing up the ranking table, Singapore overtook Frankfurt (Germany), Geneva (Switzerland), Oslo (Norway), Osaka/Kobe (Japan), London (UK) and Tokyo (Japan), all of which were ranked above Singapore in 2011. Interestingly, the countries where these cities are in all experienced exchange rate depreciations over the 2011-2013 period. For example, the British pound depreciated by $2.45 \%$ against the US dollar; the Norwegian krone by $4.83 \%$ and most severely, the Japanese yen by $22.44 \%$. These depreciation episodes served to mask any price increases which had happened in the cities mentioned when the local prices are converted into US dollar. In contrast, since the exchange rate between the Singapore dollar and the US dollar remained stable, any increases in its local prices were fully articulated in the converted prices. Such unequal levels of currency depreciation among these countries against the US dollar helped to push up Singapore's cost of living index for expatriates vis-à-vis the cities mentioned and thus the city-state's ranking as well. Although exchange rate fluctuations were not the sole cause for the rise in Singapore's ranking, they were, however, an important contributing factor. 
The phenomenon is also observed for Singapore's ranking for ordinary residents. Between 2011 and 2013, the cost of living ranking for ordinary residents in Singapore rose from 55th to 48th. Comparing the ranking in 2013 and 2011, Singapore overtook Atlanta (USA), Berlin (Germany), Buenos Aires (Argentina), Lexington (USA), Lyon (France), Pittsburgh (USA) and Rio de Janeiro (Brazil). Again, we observe that among these cities, the exchange rates of the non-US cities depreciated over the period. In particular, the euro, which is used in France and Germany, depreciated by $4.7 \%$ against the US dollar; the Argentinean peso depreciated by $32.7 \%$ and the Brazilian real by $29.1 \%$.

\subsection{The effects of currency appreciation on expatriates and ordinary residents}

We now discuss the effects that currency appreciation may have on the lives of expatriates and ordinary residents using Singapore as an example. In particular, we highlight how a strong Singapore dollar may affect the prices of the different goods and services which they consume and the income and wealth of each group. The analysis in this section concerns a general scenario where the Singapore dollar appreciates against various currencies and not only against the US dollar. We also assume ceteris paribus, or that no other factor changes aside from the exchange rates of the Singapore dollar.

As the Singapore dollar strengthens, local prices of imports in Singapore are lowered as it now requires fewer Singapore dollars to buy one unit of foreign currency worth of imports. Consumption items which are imported thus become less expensive. This is beneficial for both expatriates and ordinary residents, but especially so for the former because expatriates are geared towards consuming high-end imported products to maintain comparatively more expensive Western lifestyles. At the same time, prices of locally produced goods, especially common foodstuffs, may also decrease, as these goods face greater competition from cheaper imported close substitutes. Goods which are produced using imported inputs will see a greater drop in prices. In contrast to goods, the local prices of most services consumed by expatriates and ordinary residents, such as the price of haircuts, are unlikely to be affected. As these services are largely non-tradable, there are no foreign substitutes creating competitive pressure.

Meanwhile, an appreciating Singapore dollar makes the prices of Singapore's exports in the international market less competitive. As a result, international demands for Singapore's exports are likely to be reduced. The extent of this reduction depends on the price elasticity of demand of overseas consumers for Singapore's exports. If demand is relatively inelastic, the decrease in quantities demanded is marginal. However, if the reverse is true, the slump in exports will be great and this may have repercussions on the employment prospects of ordinary residents working in the export sectors.

The above argument notwithstanding, a strong Singapore dollar does not have much of an impact on the income and wealth of ordinary residents. Ordinary residents are remunerated in local currency so the value of their income in terms of Singapore dollars is unaffected by the exchange rate. Since ordinary residents save and invest mostly in local assets, such as Singapore dollar-denominated time deposits or savings with the Central Provident Fund (CPF), exchange rate fluctuations also do not have much impact on the value of their wealth. However this argument may not apply to the upper strata of the population, as they may also hold foreign assets; the above arguments are largely 
applicable to most ordinary residents. Owing to the strong Singapore dollar, some imported goods consumed by ordinary residents may experience price declines. Nonetheless, the total resources available for ordinary residents to support their lifestyles are not affected by the strength of the Singapore dollar.

In contrast, an appreciating Singapore dollar has an income effect on expatriates. The exact nature of the effect, however, depends on their remuneration arrangements. If an expatriate is paid in his home currency, or in US dollar, the value of his income in terms of Singapore dollar will decrease. He will thus have fewer resources at his disposal to support his lifestyle. On the other hand, if the expatriate is compensated in Singapore dollar, the value of his income is not reduced. In fact, a strong Singapore dollar may help to make more income available for consumption because it lessens the burden of remittances. It is likely that the expatriate has to send a portion of his income back to his home country, either to support dependants back home or to settle outstanding financial commitments such as mortgages. A strong Singapore dollar allows the expatriate to remit this pre-set amount of money with fewer Singapore dollars, thus leaving him with more income for consumption.

These conclusions are important to either reinforce, justify existing policies or as options for fine-tuning policies with respect to exchange rates. In turn, exchange rate policies affect trade policies among other matters. Singapore as one of the most open economies (in terms of total trade to gross domestic product) does watch its exchange rate policy conscientiously.

The effects we have described in this analysis do manifest in reality, subject to a host of other relevant factors (e.g., transport costs, oil prices). A strong Singapore dollar is somewhat beneficial as it helps to mitigate imported inflation. Nonetheless, its appreciation should be carefully managed because of the potential adverse consequences on exporting activities. Income-wise, expatriates are more affected than ordinary residents by exchange rate fluctuations. Whether a strong Singapore dollar is a boon or a bane for expatriates depends on their remuneration arrangements with their firms.

\section{Comparing cost of living across geographical regions}

An interesting observation emerges when we compare the cost of living in different cities across geographical regions. Cities in the West tend to have higher cost of living for ordinary residents than cities elsewhere. On the other hand, there is no similar pattern in the geographical distribution of cities according to their cost of living for expatriates. In other words, an Asian city, such as Shanghai, is likely to have a lower cost of living for ordinary residents as compared to a city in Western Europe, such as Amsterdam. However, it may be ranked higher or lower than the latter in terms of cost of living for expatriates.

Figure 1 illustrates the pattern concerning the cost of living for ordinary residents. It graphs the cost of living indices for ordinary residents in all cities in our study in 2013. The horizontal axis reflects the index values while the different cities are plotted on the vertical axis. The longer the bar, the higher the index value and hence the more expensive for ordinary residents in the particular city as compared to the other cities in 2013. The different colours of the bars represent the region to which each city belongs. 
Figure 1 Cost of living indices for ordinary residents in 103 world's major cities in 2013 by geographical regions (see online version for colours)

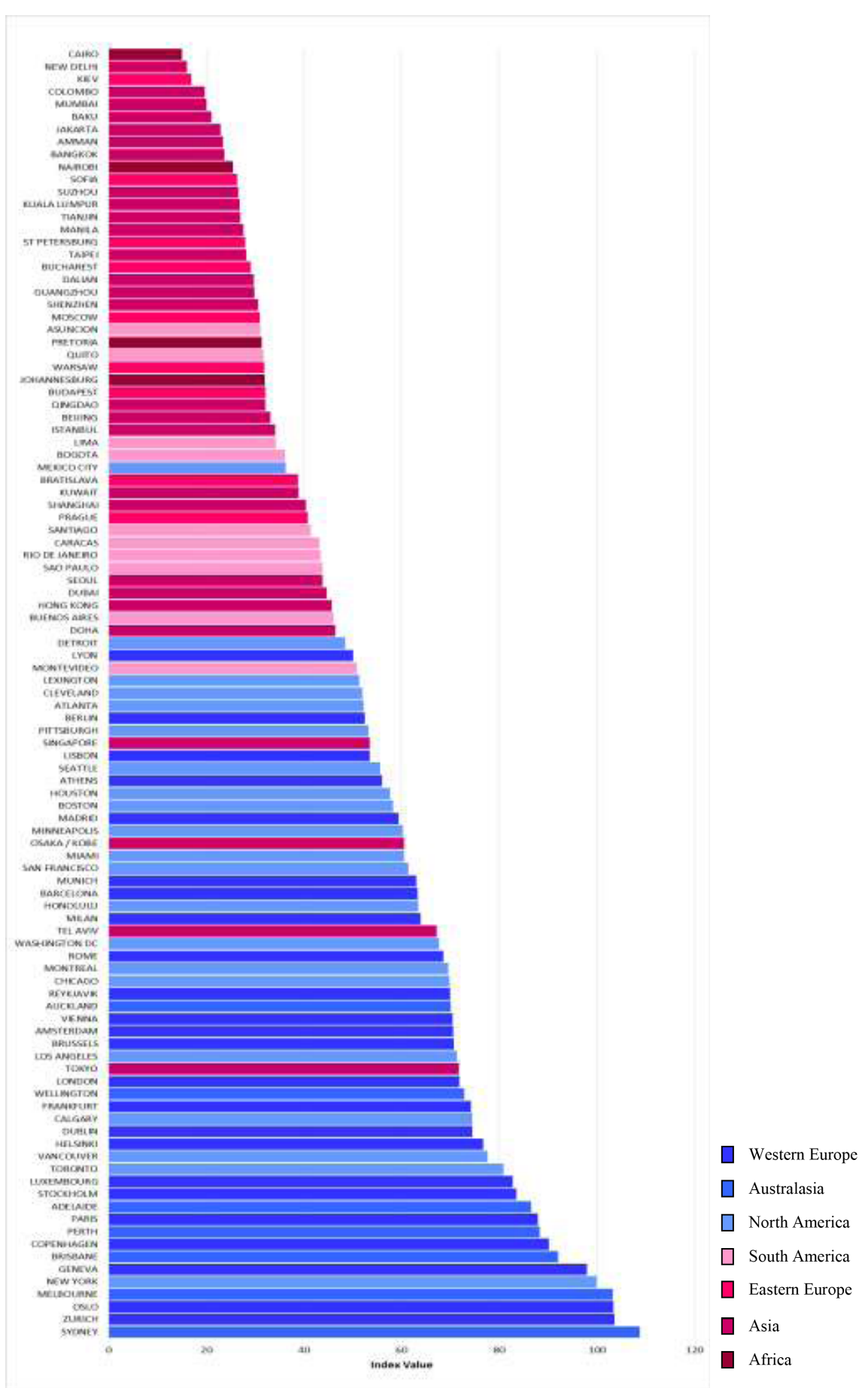

Source: Tan et al. (2015) 
As apparent from Figure 1, cities in Western Europe are among the most expensive cities for ordinary residents. They are followed by cities in Australasia (Australia and New Zealand) and North American cities. On the other hand, African and Asian cities tend to be the cheapest, followed by Eastern European cities and cities in South America. There are of course exceptions. A handful of Asian cities are as expensive as their Western counterparts. The cost of living for ordinary residents in Tokyo, for instance, was more or less similar to that in London and Los Angeles while cost in Singapore was comparable to that in Lisbon and Pittsburgh. Nevertheless, the general pattern is still one of which cities in the West have a higher cost of living for ordinary residents than cities in the rest of the world, notably in Asia.

This is not so much of the cultural connotations of the Western lifestyles vis-à-vis the Eastern ones. It has more to do with the West being relatively more developed in terms of economic growth and development, while the East comprises more developing economies which neither have attained the take-off stage nor reached the economic maturity of developed countries. In turn, the cost structure of tradable and non-tradable becomes more relevant. There are exceptions such as Tokyo and Singapore, which are Asian cities with economic maturation on par with their Western counterparts.

The explanation for the observed pattern lies in the difference in the cost structure of non-traded goods and services (especially in the case of services) between the Western countries and other less developed countries. Locally provided non-tradable services such as haircuts constitute an integral part of the ordinary residents' consumption basket and therefore they are important determinants of the cost of living of ordinary residents in a country. By their very nature, the service industries are labour intensive and the average wages in Western Europe, Australasia and North America are generally significantly higher than that in Africa, Asia, Eastern Europe and South America. For example, the mean of the average gross hourly wages in all Western European cities in our study in 2013 was US\$27.16 while that in the Asian cities was only US\$6.48. As a result, the prices of services in the West are more expensive than comparable services in Asia and elsewhere.

It is of little surprise that our cost of living index for ordinary residents is able to capture the differences in prices of non-traded goods and services across countries. Such differences are reflected through purchasing power parity (PPP)-based exchange rates. Our cost of living index for ordinary residents incorporates data from the World Bank's ICP, which is designed to yield survey data from around the world in order to calculate PPP-based exchange rates.

In contrast to the clear pattern observed for ordinary residents, there is no discernible variation in the cost of living for expatriates regardless of the geographic distribution of the cities. This is perhaps because expatriates everywhere are geared towards high-end imports to maintain Western lifestyles. As such, their costs of living are mainly affected by exchange rate fluctuations rather than local factors. The lack of varying patterns in cost of living for expatriates is evident in Figure 2, which graphs the cost of living indices for expatriates in all cities in our study in 2013. Similar to Figure 1, the vertical axis plots the cities while the horizontal axis plots the index values. The different colours represent the geographical region which each city belongs. 
Figure 2 Cost of living indices for expatriates in 103 world's major cities in 2013 by geographical regions (see online version for colours)

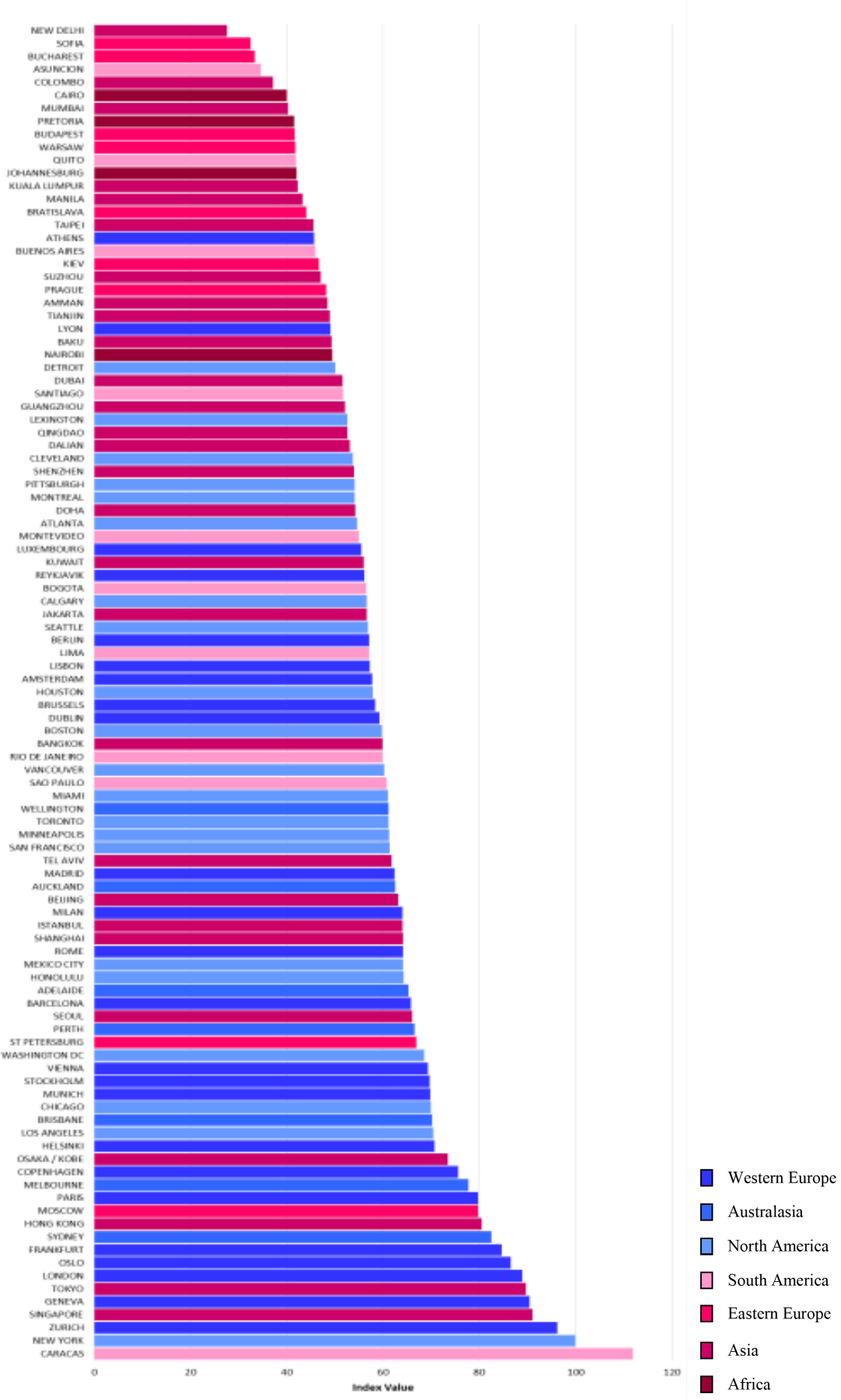

Source: Tan et al. (2015) 


\section{Conclusions}

The pace of urbanisation has risen rapidly across the globe in recent years. Considering that the overwhelming majority of economic activity now takes place in cities, the speed and scale of urbanisation has critical implications for living costs across the world. International benchmarks for major cities become crucial in this context. Given this background, this paper has examined costs of living in the world's major cities for both expatriates and ordinary residents accounting for exchange rate effects. This paper, based on earlier pioneering work by Tan et al. (2015) and Tan and Luu (2016), makes an effort to contribute to the academic literature by providing a more nuanced understanding of cities than existing popular indices do. It reveals that cost of living indices should take into account the fact that the residents of a city would invariably comprise the locals and expatriates, with their differing lifestyles and spending patterns. These differences would inevitably result in diverging costs of living for locals and expatriate denizens. With this divergence in mind, it becomes imperative for cost of living studies to make a clear distinction between the cost of living for locals and expatriates across cities worldwide. This paper along with preceding work by Tan et al. (2015) and Tan and Luu (2016) addresses this gap.

Further, it is important to account for the effects that exchange rates have on cost of living rankings while computing cost of living indices, as conversion of local prices into a common currency is imperative for any ranking of cities in different parts of the world. Considering that such computations are affected by exchange rate levels across different cities, this paper empirically analyses the cases of Singapore and Hong Kong to understand the impact of exchange rates on their cost of living rankings. Our study through simulation analysis is able to assess the impact of exchange rate fluctuations on the rankings. In Singapore's case, the appreciation of the Singapore dollar has led to its rise in the cost of living rankings for both expatriates and ordinary residents. Whereas in the case of Hong Kong, the impact of exchange rate fluctuations for both expatriates and ordinary residents is minimal owing to the Hong Kong dollar's peg to the US dollar. This is borne out by the fact that Hong Kong's simulated rankings for both expatriates and ordinary residents' costs of living are almost always identical to its original rankings for the period covered in this study. However, this paper also reveals that simulation analysis does not cover every facet of the exchange rate analysis approach. It asserts that exchange rate fluctuations in other cities (based in other countries) could also influence the cost of living rankings of the concerned city. The rising cost of living ranking for expatriates in Singapore between the period 2011-2013 is cited as an example of the considerable impact wrought by exchange rate fluctuations in other cities elsewhere; the depreciation of the British pound, Norwegian krone and the Japanese yen against the US dollar played a major role in leading to the rise in Singapore's cost of living ranking for expatriates for the 2011-2013 period (a period of relative stability for the Singapore-US dollar exchange rate).

In addition, our study reveals that cities in the developed Western countries are more expensive for ordinary residents than cities in less developed countries elsewhere, especially in Asia. We attribute this to structural differences in labour cost between these two sets of countries. Non-tradable services (e.g., haircuts) are currently an integral part of the ordinary residents' consumption basket. The service industries tend to be relatively more labour intensive and the average wages in the more developed West are generally 
significantly higher than wage levels in the rest of the world. Consequently, services in the West are more expensive and this invariably leads to higher living costs for ordinary residents in the West.

The strength of the cost of living index for ordinary residents presented in this paper lies in its ability to effectively capture the variations in prices of non-traded goods and services across countries. These differences are reflected through PPP exchange rates. Conversely, the index for expatriates did not discern similar variations in the cost of living for expatriates regardless of the cities' location. This could be attributed to the high-end import dependent Western lifestyles of expatriates everywhere, which largely subjects their costs of living to exchange rate fluctuations rather than local factors.

As for future research agenda, a number of caveats or assumptions made may be re-examined to incorporate rethinking and fine-tuning. One area may be to incorporate some analysis on the net effect of the substitution effect and income effect of price changes, which in our case is indirectly due to the strong Singapore dollar rather than any direct change in prices by the sellers or any goods and services tax. Thus the changes in the composition of consumer baskets over time as longitudinal studies may be interesting, as reflected in the composition of retained imports for consumption by expatriates and ordinary citizens. Cost of living studies ought to pay greater attention to the concerns and lifestyles of ordinary citizens, as they being considerably less mobile than expatriates in their choice of country of residence, are the ultimate stakeholders in any economy. Finally, future research studies could also focus on taking in to account the possible role of exchange rate fluctuations as one of the determinants of designing compensation packages for expatriates.

\section{References}

Afrait, S.N. (2004) The Price Index and Its Extension: A Chapter in Economic Measurement, Routledge, New York.

Abraham, K.G., Greenlees, J.S. and Moulton, B.R. (1998) 'Working to improve the consumer price index', Journal of Economic Perspectives, Vol. 12, No. 1, pp.27-36.

Braithwait, S.D. (1980) 'The substitution bias of the Laspeyres price index: an analysis using estimated cost-of-living indexes', The American Economic Review, Vol. 70, No. 1, pp.64-77.

Biemann, T. and Andresen, M. (2010) 'Self-initiated foreign expatriates versus assigned expatriates: two distinct types of international careers?', Journal of Managerial Psychology, Vol. 25, No. 4, pp.430-448.

Berndt, E.R., Griliches, Z. and Rappaport, N.J. (1995) 'Econometric estimates of price indexes for personal computers in the 1990s', Journal of Econometrics, Vol. 68, No. 1, pp.243-68.

Boskin, M., Dulberger, E., Gordon, R., Griliches, Z. and Jorgenson, D. (1998) 'Consumer prices, the consumer price index, and the cost of living', Journal of Economic Perspectives, Vol. 12, No. 1, pp.3-26.

Dabic, M., González-Loureiro, M. and Harvey, M. (2015) 'Evolving research on expatriates: what is 'known' after four decades (1970-2012)', The International Journal of Human Resource Management, Vol. 26, No. 3, pp.316-337.

Dumagan, J.C. and Mount, T.D. (1997) Re-examining the Cost-of-Living Index and the Biases of Price Indices: Implications for the U.S. CPI, Department of Commerce Working Paper ESA/OPD, p.97-5.

Economist Intelligence Unit (2015) Worldwide Cost of Living 2015: Which City is the Most Expensive to Live in? Which City is the Cheapest? [online] http://ifuturo.org/ documentacion/WCOLMarch.pdf (accessed 8 March 2016). 
Goldberger, A. and Gamaletsos, T. (1970) 'A cross-country comparison of consumer expenditure patterns', European Economic Review, Vol. 1, No. 3, pp.357-400.

Gordon, R.J. and Griliches, Z. (1997) 'Quality change and new products', The American Economic Review, Vol. 87, No. 2, pp.84-88.

McDonald, T. (2017) Is Singapore Really the World's Most Expensive City?, 7 April, BBC [online] http://www.bbc.com/capital/story/20170407-is-singapore-really-theworlds-most-expensivecity (accessed 29 April 2017).

McNulty, Y. and Brewster, C. (2016) 'The concept of business expatriates', in McNulty, Y. and Selmer, J. (Eds.): Research Handbook of Expatriates, Edward Elgar, Cheltenham.

McNulty, Y. and Brewster, C. (2017) 'Theorizing the meaning(s) of 'expatriate': establishing boundary conditions for business expatriates', The International Journal of Human Resource Management, Vol. 28, No. 1, pp.27-61.

Noe, N.M. and von Furstenberg, G.M. (1972) 'The upward bias in the consumer price index due to substitution', Journal of Political Economy, Vol. 80, No. 6, pp.1280-1286.

Pollak, R.A. (1975) 'Subindexes in the cost of living', International Economic Review, Vol. 16, No. 1, pp.135-150.

Saakho, H. (1999) The Role of Expatriate Managers in Global Economic Restructuring: Some Key Components and Restraints, Research Papers in International Business, pp.15-99, Centre for International Business Studies, South Bank University, London.

Shay, J.P. and Baack, S.A. (2004) 'Expatriate assignment, adjustment and effectiveness: an empirical examination of the big picture', Journal of International Business Studies, Vol. 35, pp.216-232.

Stigler, G.J. (1961) 'Report of the price statistics review committee', in Brady, D. et al. (Eds.): Price Statistics of the Federal Government, National Bureau of Economic Research, New York.

Suutari, V. and Tornikoski, C. (2000) Determinants of Expatriate Compensation - Findings among Expatriate Members of SEFE, LTA 4/00, pp.517-539.

Tan, K.G., Tan, K.Y., Yuan, R. and Nguyen, L.P.A. (2015) 2014 Annual Indices for Expatriates and Ordinary Residents on Cost of Living, Wages and Purchasing Power for World's Major Cities, World Scientific, Singapore.

Tan, K.G. and Luu, N.T.D. (2016) 'Measuring cost of living for ordinary residents in cities: a new index', Business and Management Studies, Vol. 2, No. 3, pp.52-77.

Triplett, J.E. (2000) Should the Cost-of-Living Index Provide the Conceptual Framework for a Consumer Price Index?, Brookings Institution [online] https://www.brookings.edu/ wp-content/uploads/2016/06/20001130.pdf (accessed 18 August 2016).

\section{Notes}

1 The Worldwide Cost of Living survey by the EIU is meant to assist human resource managers and expatriates in drawing comparisons in the cost of living across 140 cities in 93 countries. This would enable them to determine equitable compensation policies when relocating employees. See Economist Intelligence Unit $(2015$, p.7).

2 This is computed based on the yearly average exchange rates of the Singapore dollar against the US dollar. The yearly average exchange rate is calculated based on the daily average exchange rate retrieved from Bloomberg.

3 For example, according to the EIU's 2015 Worldwide Cost of Living survey, Singapore was ranked first while Hong Kong was ranked ninth out of 140 cities in terms of cost of living for expatriates (Economist Intelligence Unit, 2015). Meanwhile, the 2015 Mercer Cost of Living survey, which also tracks cost of living for expatriates, ranked Singapore fourth and Hong Kong second out of 207 cities (see http://www.mercer.com/newsroom/costof-livingsurvey.html). 
4 It is also notable that in a recent commentary by McDonald (2017) of the British Broadcasting Corporation (BBC), this research was cited as a critique to the existing cost of living indices produced by the likes of Economist Intelligence Unit. For more see, McDonald, T. (2017) Is Singapore Really the World's Most Expensive City?, 07 April, BBC [online] http://www.bbc.com/capital/story/20170407-is-singapore-really-theworlds-most-expensivecity (accessed 29 April 2017).

5 Also see Saakho (1999) who considers the role played by senior expatriate managers in global expansion strategies.

6 Table 3 (Annex) lists the 103 cities used originally in Tan et al. (2015).

7 See Tan et al. (2015) for a detailed discussion.

8 The yearly average exchange rates are calculated based on the daily average exchange rates obtained from Bloomberg. See Table 4 (Annex) for list of all yearly average exchange rates used in this study.

\section{Annex}

Table 3 List of cities

\begin{tabular}{lccc}
\hline No. & City & Country & Region \\
\hline 1 & Adelaide & Australia & Australasia \\
2 & Amman & Jordan & Asia \\
3 & Amsterdam & Netherlands & Western Europe \\
4 & Asuncion & Paraguay & South America \\
5 & Athens & USA & Western Europe \\
6 & Atlanta & New Zealand & North America \\
7 & Auckland & Azerbaijan & Australasia \\
8 & Baku & Thailand & Asia \\
9 & Bangkok & Spain & Asia \\
10 & Barcelona & China & Western Europe \\
11 & Beijing & Germany & Asia \\
12 & Berlin & Colombia & Western Europe \\
13 & Bogota & USA & South America \\
14 & Boston & Slovakia & North America \\
15 & Bratislava & Australia & Eastern Europe \\
16 & Brisbane & Belgium & Australasia \\
17 & Brussels & Romania & Western Europe \\
18 & Bucharest & Hungary & Eastern Europe \\
19 & Budapest & Argentina & Eastern Europe \\
20 & Buenos Aires & Egypt & South America \\
21 & Cairo & Canada & Africa \\
22 & Calgary & Venezuela & North America \\
23 & Caracas & USA & South America \\
24 & Chicago & & North America \\
\hline & Tangtan &
\end{tabular}

Source: Tan et al. (2015) 
Table 3 List of cities (continued)

\begin{tabular}{|c|c|c|c|}
\hline No. & City & Country & Region \\
\hline 25 & Cleveland & USA & North America \\
\hline 26 & Colombo & Sri Lanka & Asia \\
\hline 27 & Copenhagen & Denmark & Western Europe \\
\hline 28 & Dalian & China & Asia \\
\hline 29 & Detroit & USA & North America \\
\hline 30 & Doha & Qatar & Asia \\
\hline 31 & Dubai & United Arab Emirates & Asia \\
\hline 32 & Dublin & Ireland & Western Europe \\
\hline 33 & Frankfurt & Germany & Western Europe \\
\hline 34 & Geneva & Switzerland & Western Europe \\
\hline 35 & Guangzhou & China & Asia \\
\hline 36 & Helsinki & Finland & Western Europe \\
\hline 37 & Hong Kong & Hong Kong, China & Asia \\
\hline 38 & Honolulu & USA & North America \\
\hline 39 & Houston & USA & North America \\
\hline 40 & Istanbul & Turkey & Asia \\
\hline 41 & Jakarta & Indonesia & Asia \\
\hline 42 & Johannesburg & South Africa & Africa \\
\hline 43 & Kiev & Ukraine & Eastern Europe \\
\hline 44 & Kuala Lumpur & Malaysia & Asia \\
\hline 45 & Kuwait & Kuwait & Asia \\
\hline 46 & Lexington & USA & North America \\
\hline 47 & Lima & Peru & South America \\
\hline 48 & Lisbon & Portugal & Western Europe \\
\hline 49 & London & Great Britain & Western Europe \\
\hline 50 & Los Angeles & USA & North America \\
\hline 51 & Luxembourg & Luxembourg & Western Europe \\
\hline 52 & Lyon & France & Western Europe \\
\hline 53 & Madrid & Spain & Western Europe \\
\hline 54 & Manila & Philippines & Asia \\
\hline 55 & Melbourne & Australia & Australasia \\
\hline 56 & Mexico City & Mexico & North America \\
\hline 57 & Miami & USA & North America \\
\hline 58 & Milan & Italy & Western Europe \\
\hline 59 & Minneapolis & USA & North America \\
\hline 60 & Montevideo & Uruguay & South America \\
\hline 61 & Montreal & Canada & North America \\
\hline 62 & Moscow & Russia & Eastern Europe \\
\hline 63 & Mumbai & India & Asia \\
\hline 64 & Munich & Germany & Western Europe \\
\hline
\end{tabular}

Source: Tan et al. (2015) 
Table 3 List of cities (continued)

\begin{tabular}{|c|c|c|c|}
\hline No. & City & Country & Region \\
\hline 65 & Nairobi & Kenya & Africa \\
\hline 66 & New Delhi & India & Asia \\
\hline 67 & New York & USA & North America \\
\hline 68 & Osaka/Kobe & Japan & Asia \\
\hline 69 & Oslo & Norway & Western Europe \\
\hline 70 & Paris & France & Western Europe \\
\hline 71 & Perth & Australia & Australasia \\
\hline 72 & Pittsburgh & USA & North America \\
\hline 73 & Prague & Czech Republic & Eastern Europe \\
\hline 74 & Pretoria & South Africa & Africa \\
\hline 75 & Qingdao & China & Asia \\
\hline 76 & Quito & Ecuador & South America \\
\hline 77 & Reykjavik & Iceland & Western Europe \\
\hline 78 & Rio de Janeiro & Brazil & South America \\
\hline 79 & Rome & Italy & Western Europe \\
\hline 80 & San Francisco & USA & North America \\
\hline 81 & Santiago & Chile & South America \\
\hline 82 & Sao Paulo & Brazil & South America \\
\hline 83 & Seattle & USA & North America \\
\hline 84 & Seoul & South Korea & Asia \\
\hline 85 & Shanghai & China & Asia \\
\hline 86 & Shenzhen & China & Asia \\
\hline 87 & Singapore & Singapore & Asia \\
\hline 88 & Sofia & Bulgaria & Eastern Europe \\
\hline 89 & St Petersburg & Russia & Eastern Europe \\
\hline 90 & Stockholm & Sweden & Western Europe \\
\hline 91 & Suzhou & China & Asia \\
\hline 92 & Sydney & Australia & Australasia \\
\hline 93 & Taipei & Taiwan, China & Asia \\
\hline 94 & Tel Aviv & Israel & Asia \\
\hline 95 & Tianjin & China & Asia \\
\hline 96 & Tokyo & Japan & Asia \\
\hline 97 & Toronto & Canada & North America \\
\hline 98 & Vancouver & Canada & North America \\
\hline 99 & Vienna & Austria & Western Europe \\
\hline 100 & Warsaw & Poland & Eastern Europe \\
\hline 101 & Washington DC & USA & North America \\
\hline 102 & Wellington & New Zealand & Australasia \\
\hline 103 & Zurich & Switzerland & Western Europe \\
\hline
\end{tabular}

Source: Tan et al. (2015) 
Table 4 Yearly average exchange rates in 103 world's major cities (local currency units per US dollar), 2005-2013

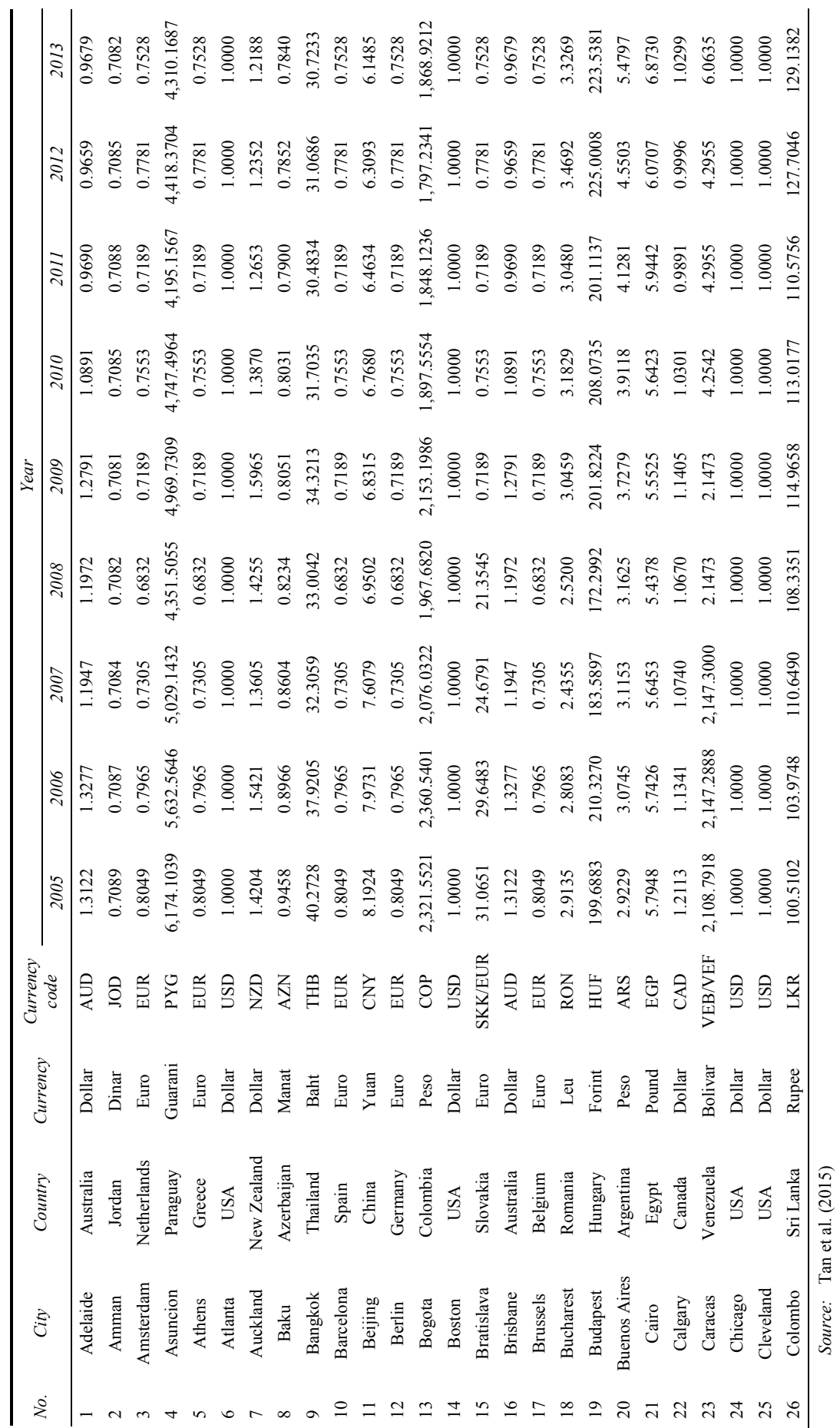


Table 4 Yearly average exchange rates in 103 world's major cities (local currency units per US dollar), 2005-2013 (continued)

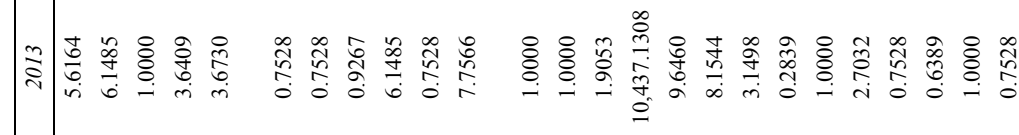

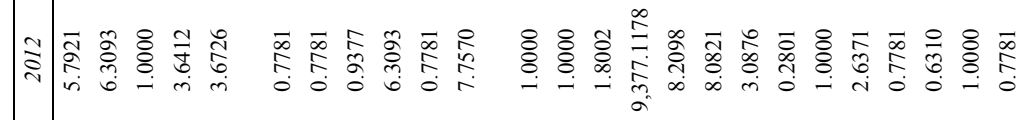

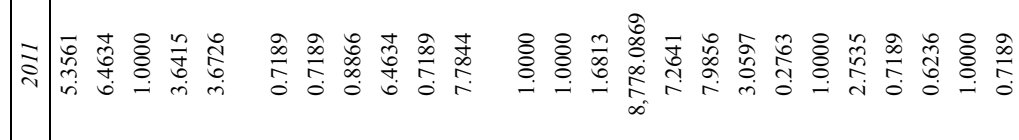

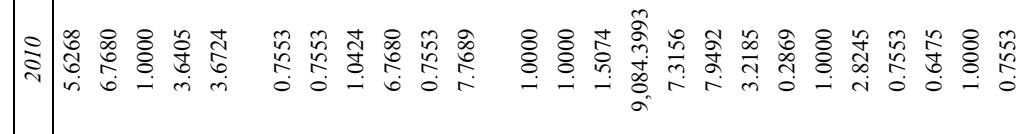

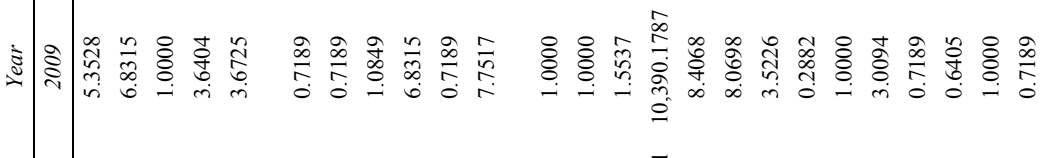

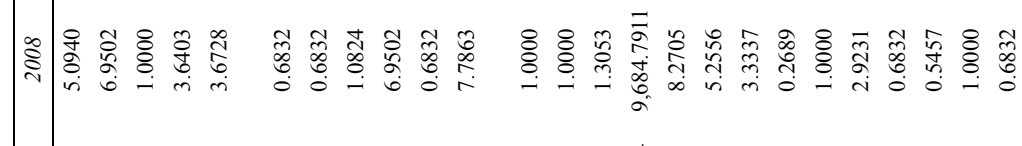

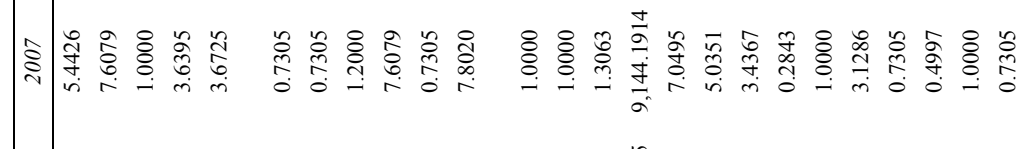

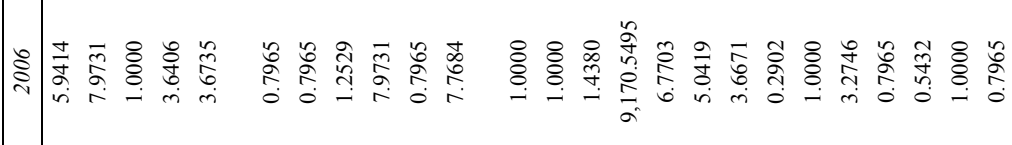

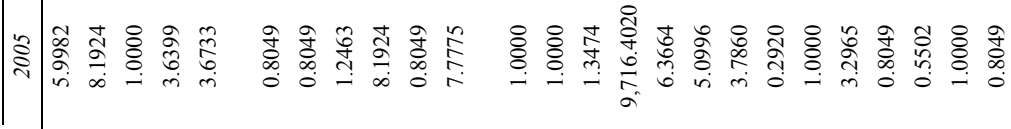

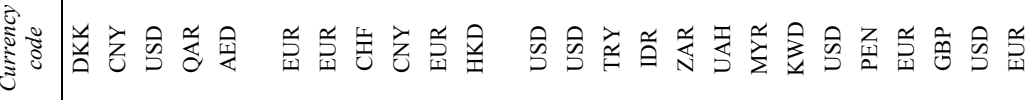

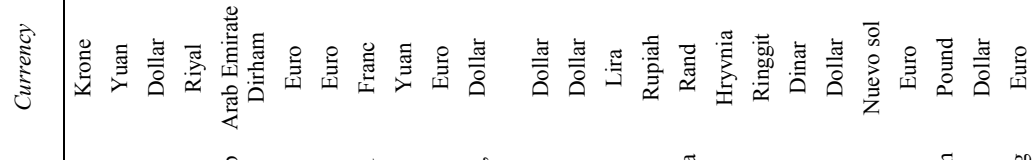

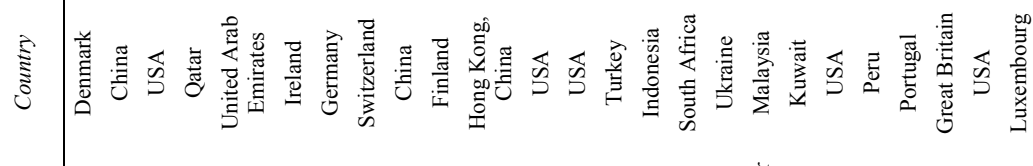

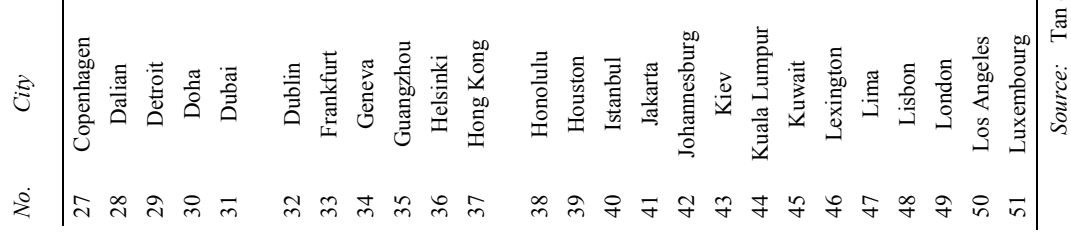


Table 4 Yearly average exchange rates in 103 world's major cities (local currency units per US dollar), 2005-2013 (continued)

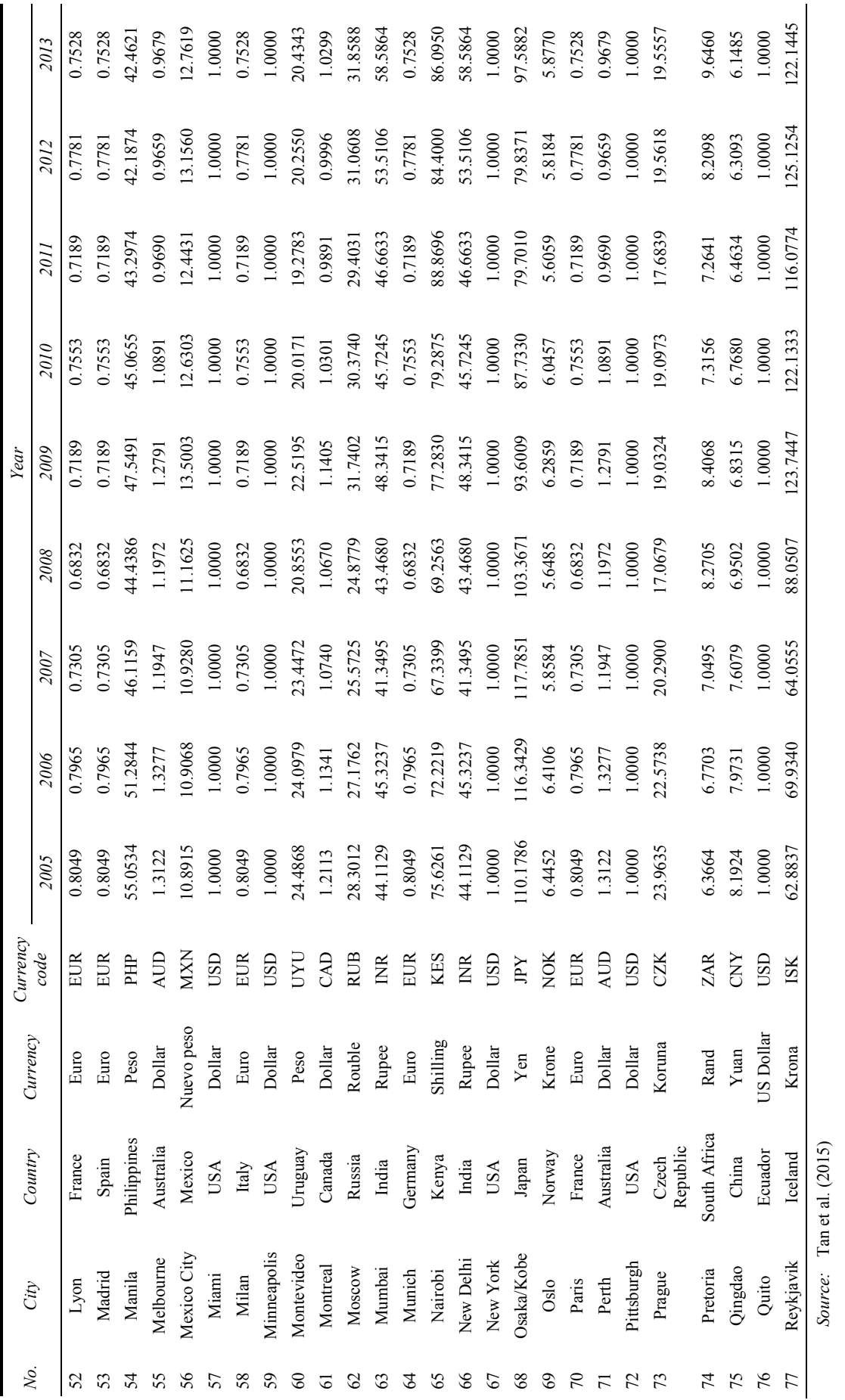


Table 4 Yearly average exchange rates in 103 world's major cities (local currency units per US dollar), 2005-2013 (continued)

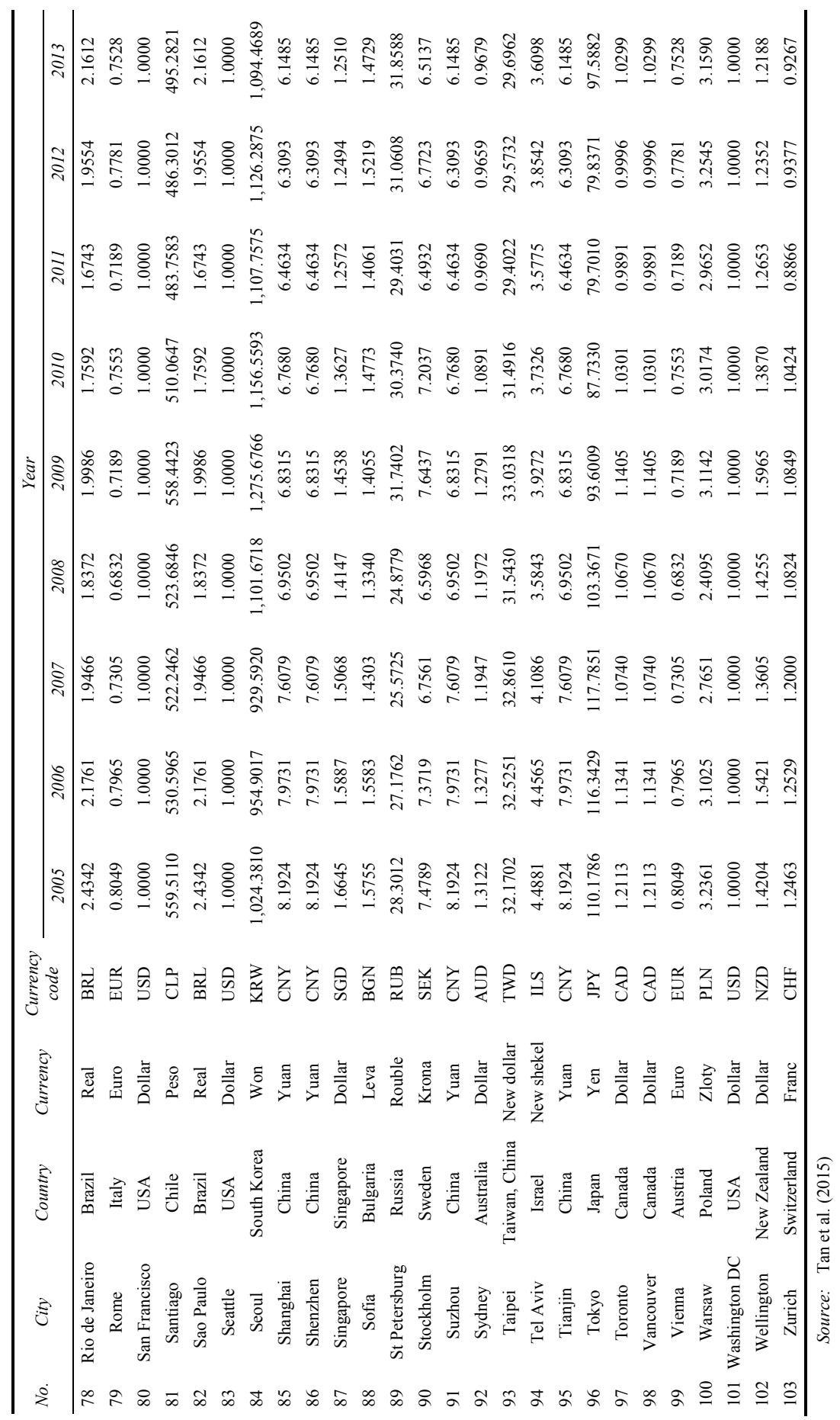

